\title{
Rancang Bangun Sistem Kendali Kecepatan Putaran Motor Dc Berbasis Logika Fuzzy Untuk Mesin Pengaduk Hasil Pertanian (Studi Kasus Pengadukan Biji Kedelai)
}

\section{(Design of Motor DC Speed Control System Based of Fuzzy Logic for Agricultural Stirrers (Case Study of Stirring Soybean Seeds))}

\author{
Reni Pratiwi ${ }^{(*)}$, Abdul Waris ${ }^{2)}$ dan Salengke ${ }^{3)}$ \\ 1) Program Studi Keteknikan Pertanian Universitas Hasanuddin \\ 2) Program Studi Keteknikan Pertanian Universitas Hasanuddin \\ ${ }^{3)}$ Program Studi Keteknikan Pertanian Universitas Hasanuddin \\ $\left.{ }^{*}\right)$ Email korespondensi: renipratiwi13@gmail.com
}

\begin{abstract}
ABSTRAK
Tujuan penelitian ini adalah menghasilkan kontrol kecepatan putaran motor dc dengan kinerja yang baik untuk mesin pengaduk milik UKM Arbi. Metode penelitian ini yaitu metode rancang bangun yang terdiri identifikasi masalah, studi literatur, perancangan sistem hardware dan software, serta pengujian dengan menggunakan biji kedelai sebagai beban. Perlakuan pengujian dilakukan dengan menetapkan setting point pada kecepatan $130 \mathrm{rpm}, 190 \mathrm{rpm}$, dan $252 \mathrm{rpm}$ pada beban $2.23 \mathrm{Nm}$ dan $3.73 \mathrm{Nm}$. Hasil pengujian tanpa kontrol menunjukkan kecepatan motor tidak mampu mencapai nilai setting point pada ketiga kecepatan tersebut. Hasil pengujian dengan menggunakan kontrol logika fuzzy menghasilkan kecepatan motor yang mampu mencapai nilai setting point, kecepatan putaran yang naik secara bertahap (softstarting), tidak terjadi overshoot atau tidak terjadinya lonjakan arus, tidak memiliki offset, dan mampu menghasilkan kinerja sistem kontrol yang stabil.
\end{abstract}

Kata Kunci: logika fuzzy, kinerja sistem kontrol

\section{PENDAHULUAN}

\section{Latar Belakang}

Penggunaan motor, baik motor bakar maupun motor listrik, memegang peran penting di bidang mekanisasi pertanian karena memberikan kemudahan dalam melakukan usaha tani serta meningkatkan efisiensi penggunaan tenaga maupun waktu. Penggunaannya dimanfaatkan untuk berbagai macam keperluan, seperti motor bakar yang dimanfaatkan sebagai tenaga penggerak traktor dan motor listrik yang lebih banyak digunakan dalam industriindustri pertanian, seperti mesin pencacah, mesin pengaduk dan pencampur, mesin penggilingan padi, dsb.

Motor listrik digunakan sebagai penggerak mesin pengaduk milik Usaha Kecil Menengah (UKM) Arbi. UKM tersebut merupakan usaha kecil dari Kelompok Tani "Sipakainge" Kabupaten Sinjai untuk mengolah berbagai hasil pertanian menjadi produk pangan, seperti VCO. Mesin tersebut memiliki masalah ketika dioperasikan yaitu tidak terkendalinya kecepatan putaran motor menyebabkan bahan-bahan yang diaduk kerap kali keluar dari bak wadah pengaduk. Selain itu, motor memiliki kecepatan yang 
tidak konstan ketika ada perubahan beban. Menurut keterangan Rasyid, ketua UKM tersebut, mereka membutuhkan kecepatan putaran yang naik secara bertahap (softstarting), agar mencegah bahan yang diaduk keluar dari bak pengaduk, mengurangi suara yang bising yang dihasilkan, mencegah adanya potensi kerusakan bahan yang diaduk, dan menghasilkan kecepatan yang stabil.

Kestabilan kecepatan putaran motor memengaruhi hasil pengadukan. Gunterus (1994) menyatakan sistem yang tidak stabil dihindari karena dapat membahayakan operator, perlatan yang digunakan, mutu produk yang dihasilkan, serta efisiensi penggunaannya.

Pemberian pengontrol dapat mengatasi permasalahan tersebut. Salah satu jenis pengontrol yang digunakan saat ini adalah logika fuzzy. Kelebihan pengontrol ini adalah dalam penalarannya menggunakan proses penalaran secara bahasa (linguistic) sehingga dalam perancangannya tidak memerlukan pemodelan matematika yang rumit dari objek yang dikendalikan.

Mengingat pentingnya pemberian sistem kontrol pada mesin pengaduk milik tersebut, maka tugas akhir ini merancang sistem kendali kecepatan putaran motor mesin pengaduk sehingga kecepatan putaran dapat dikendalikan sesuai dengan keinginan operator maupun kebutuhan rpm suatu bahan.

Metode pengendalian kecepatan putaran motor dalam perancangan ini menggunakan logika fuzzy. Logika fuzzy memiliki beberapa keuntungan dibandingkan dengan jenis pengontrol lain, diantaranya kemampuannya dalam proses penalaran secara bahasa (linguistic reasoning) sehingga dalam perancangannya tidak memerlukan persamaan matematika dari objek yang dikendalikan.

\section{Rumusan Masalah}

1. Bagaimana merancang sistem kendali kecepatan putaran motor pada mesin pengaduk dengan menggunakan kendali logika fuzzy?

2. Bagaimana kinerja sistem kontrol pada mesin pengaduk?

\section{Tujuan dan Manfaat}

Tujuan penelitian ini adalah untuk menghasilkan sistem kendali mesin pengaduk berbasis logika fuzzy dan mengetahui kinerja sistem kontrol pada mesin pengaduk.

Manfaat yang diperoleh dari penelitian ini adalah:

1. Sistem kontrol dapat diterapkan pada mesin pengaduk.

2. Bagi pengembangan ilmu, penelitian ini menjadi referensi mengendalikan putaran motor dc menggunakan logika fuzzy untuk mesin pengaduk bahan pertanian.

\section{Batasan Masalah}

1. Penelitian ini berfokus pada sistem kendali kecepatan putaran motor.

2. Biji kedelai digunakan sebagai beban pengadukan.

3. Mikrokontroler yang digunakan adalah ATMega32.

4. Jenis inferensi fuzzy (fuzzy inference) yang digunakan adalah metode Sugeno.

\section{METODOLOGI PENELITIAN}

\section{Alat dan Bahan}

Alat yang digunakan dalam penelitian ini adalah solder, laptop, dan mesin pengaduk. Bahan yang digunakan yaitu sensor rotary encoder, sistem minimum dan mikrokontroler AVR ATMega 32, SSR, LCD, kabel, transistor, resistor, papan PCB, dan biji kedelai. Software yang digunakan yaitu CV AVR, downloader AVROP II, Serial Port MSI, dan MATLAB.

\section{Prosedur Penelitian}

Penelitian ini memiliki alur prosedur sebagai berikut: 
Jurnal AgriTechno. Vol. 12 (1): 44-55

https://doi.org/10.20956/at.v12i1.185

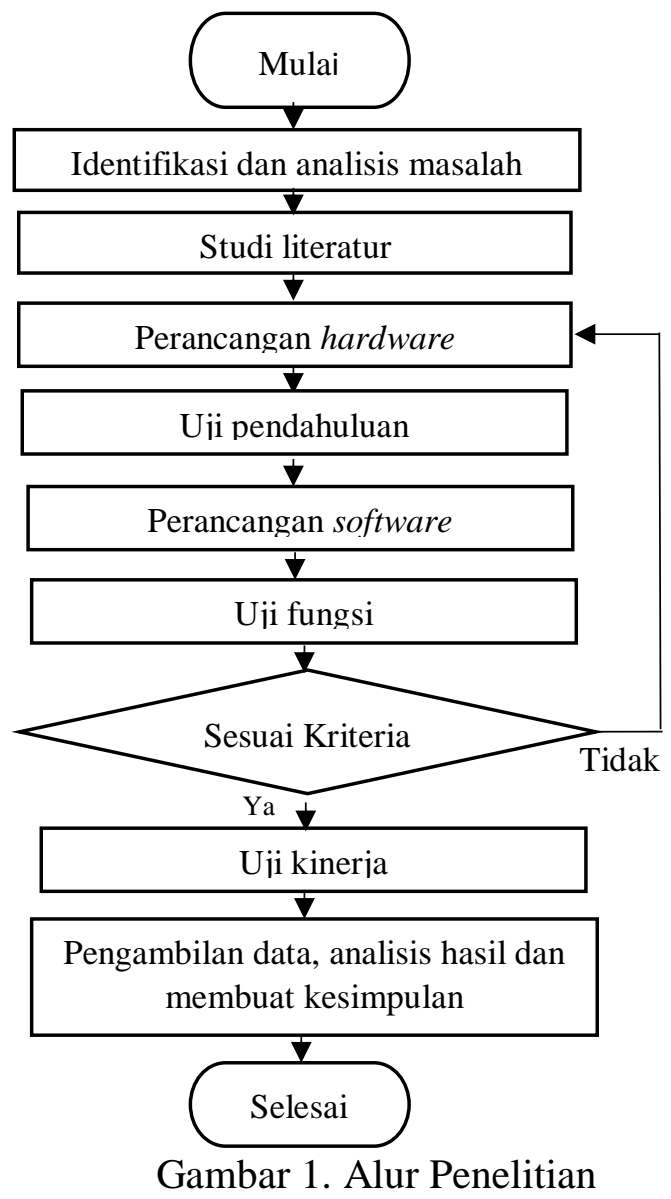

\section{Perancangan Sistem Kendali Kecepatan Putar Motor}

Perancangan sistem kendali kecepatan putar motor adalah sebagai berikut:

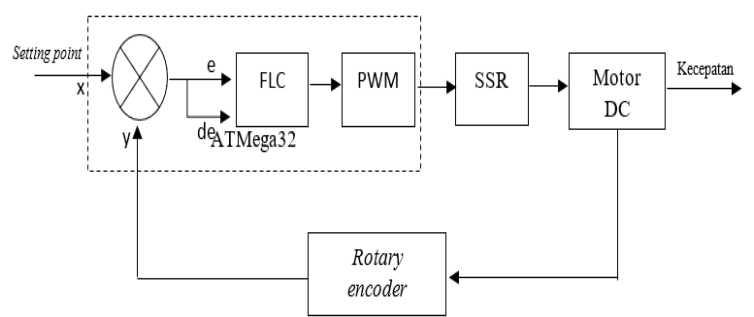

Gambar 2. Sistem Kendali Kecepatan Motor

\section{Uji Pendahuluan}

Tujuan dari uji pendahuluan untuk mengetahui hubungan PWM yang diberikan terhadap kecepatan motor yang dihasilkan dan mengetahui perbedaan kecepatan pada poros pengaduk dan poros motor.

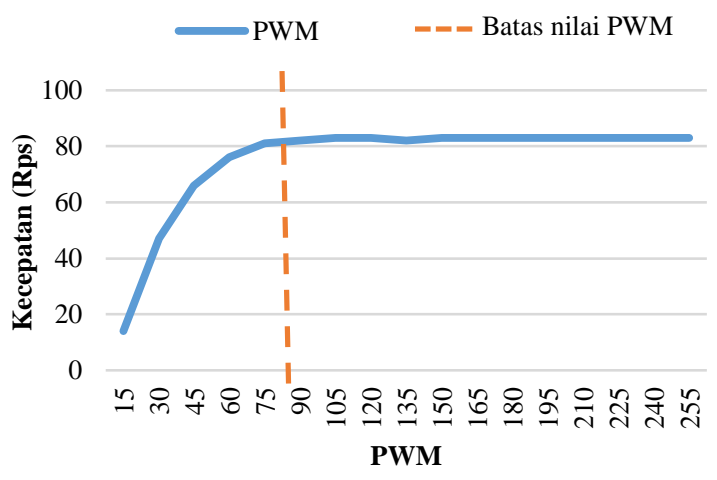

Gambar 3. Grafik Hubungan Antara Kecepatan dan PWM

Grafik menunjukkan hubungan antara pwm dan rps tidak linear. Kecepatan motor dengan pemberian nilai diatas nilai 75 pwm tidak mengalami perubahan kecepatan. Oleh karena itu, dalam penelitian ini, dilakukan pengambilan nilai PWM di area linear, yaitu 15 - 75 PWM. Rentang nilai tersebut juga menjadi acuan dalam pemilihan rentang kecepatan putaran motor dan perancangan fuzzy.

Berdasarkan hasil pengukuran, kecepatan puataran pada poros pengaduk dan poros motor berbeda. Hubungan kecepatan tersebut dapat dilihat pada Tabel 1.

Tabel 1. Perbandingan Kecepatan Motor Poros Atas dan Poros Pengaduk

\begin{tabular}{ccc}
\hline \multicolumn{2}{c}{$\begin{array}{c}\text { Kecepatan Motor } \\
\text { (Poros Atas) }\end{array}$} & $\begin{array}{c}\text { Kecepatan Poros } \\
\text { Pengaduk } \\
\text { (Rpm) }\end{array}$ \\
\cline { 1 - 2 } Rps & Rpm & 62 \\
\hline 20 & 1200 & \\
40 & 2400 & 130 \\
60 & 3600 & 190 \\
80 & 4800 & 252 \\
\hline
\end{tabular}

\section{Perancangan Software}

Perancangan unit kendali logika fuzzy menggunakan bantuan perangkat lunak MATLAB. Metode dasar aturan (rule-base) yang digunakan adalah metode Sugeno karena memiliki representasi yang lebih efisien daripada dan cocok untuk penggunaan teknik adaptif untuk membangun model fuzzy. 


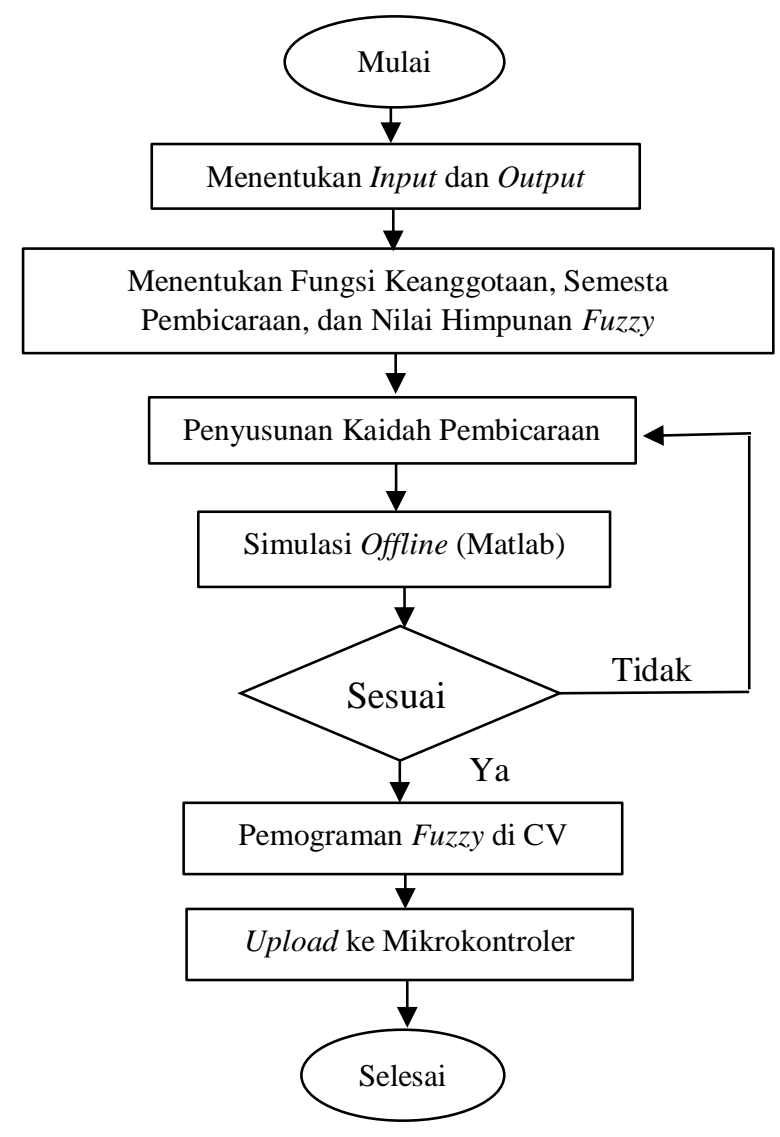

Gambar 4. Alur Perancangan Software

\section{Pendefenisian Input-Output}

Sistem fuzzy didesain memiliki 2 input, berupa error dan delta error, dan 1 output, berupa nilai PWM.

$$
\begin{array}{ll}
\mathrm{E}_{(\mathrm{n})} & =\mathrm{SP}_{(\mathrm{n})}-\operatorname{rps}_{(\mathrm{n})} \\
\mathrm{dE}_{(\mathrm{n})} & =\mathrm{E}_{(\mathrm{n})}-\mathrm{E}_{(\mathrm{n}-1)}
\end{array}
$$

dimana:

$\mathrm{E}_{(\mathrm{n})}=$ selisih kecepatan dengan setting point .

$\mathrm{E}_{(\mathrm{n}-1)}=$ error sebelumnya.

$\mathrm{SP} \quad=$ setting point .

Rps = kecepatan per detik.

$\mathrm{dE}_{(\mathrm{n})} \quad=$ perubahan selisih kecepatan sekarang dengan yang sebelumnya.

Output dalam penelitian ini adalah nilai PWM. Rentang nilai PWM yang digunakan berdasarkan hasil uji fungsional, yaitu 15-75 PWM. Nilai PWM diatas 75 tidak mampu menghasilkan perubahan kecepatan putaran motor.

\section{Penentuan Fungsi Keanggotaan, Semesta Pembicaraan, dan Nilai Himpunan Fuzzy} Bentuk fungsi keanggotaan (membership function) yang digunakan adalah bentuk segitiga. Bentuk segitiga dipilih karena menghasilkan respon yang lebih cepat dan persamaan matematika yang digunakan sederhana, yaitu menggunakan persamaan segitiga.

Masing-masing unit masukan menggunakan tujuh fungsi keanggotaan karena semakin banyak membership function, semakin baik dan halus sistem kendali yang dihasilkan. Terdapat tujuh fungsi keanggotaan, yaitu NB (negative big), NM (negative medium), NS (negative small), $\mathrm{Z}$ (zero), PS (positive small), $\mathrm{PM}$ (positive medium), $\mathrm{PB}$ (positive big).

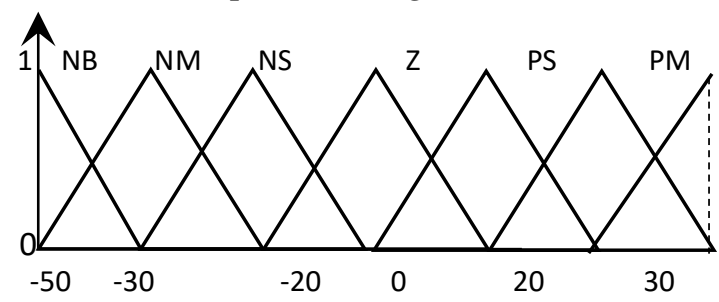

Gambar 15. Membership Function Error dan dError

Bentuk output yang digunakan adalah bentu singleton. Pemilihan bentuk singleton dilakukan karena singleton memiliki komputasi relatif sederhana dan bekerja baik dengan teknik optimasi dan adaptif (Negnevitsky, 2005).

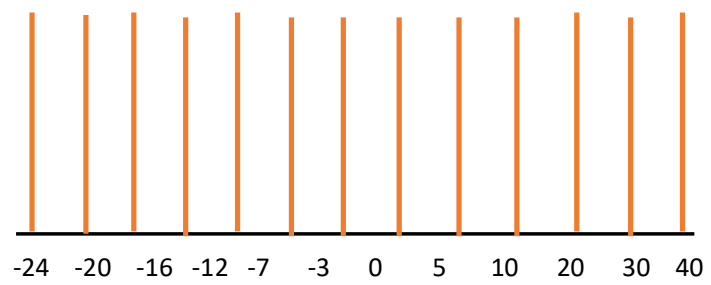

\section{Gambar 6. Membership Function PWM Bentuk Singleton}

\section{Penyusunan Kaidah Pembicaraan (Rule Base)}

Rule base (basis aturan) fuzzy dalam aplikasi teknik kontrol dinyatakan dengan "IF-THEN". Jenis operator rule base yang digunakan adalah $A N D$, artinya nilai yang diambil merupakan nilai terendah.

Mengingat jumlah membership function yang digunakan ganjil (sebanyak 7) serta memiliki angka negatif (-), zero (0), dan positif (+), maka pada penyusunan 
kaidah pembicaran, terdapat pula angka negatif (-), zero (0), dan positif (+). P1-P49 menunjukkan urutan penyusunan kaidah pembicaraan. Pola penyusunan kaidah pembicaraan merupakan pengembangan dari pola penyusunan kaidah Jamshidi (1996).

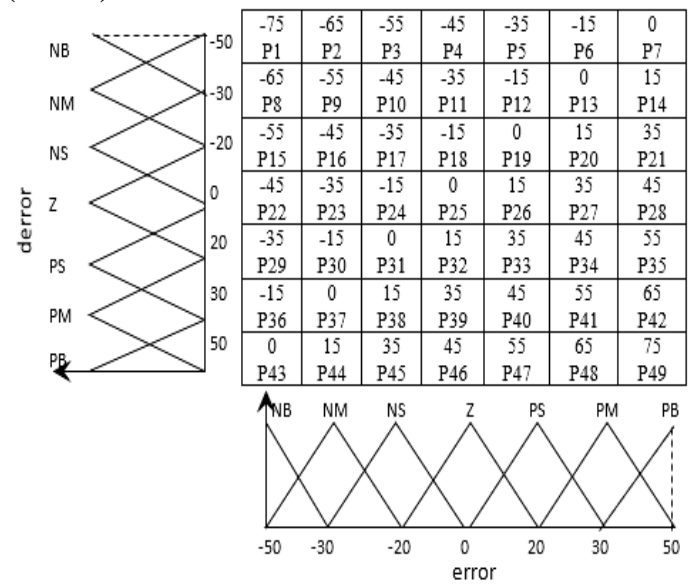

Gambar 7. Membership Function PWM Bentuk Singleton

\section{Simulasi Offline}

Simulasi offline bertujuan untuk mengetahui kinerja dari hasil kaidah pembicaraan (rule base). Hasil tersebut dapat dilih at dari bentuk surface hasil simulasi offline di MATLAB. Bentuk surface pada Gambar 18 menunjukkan bentuk respon kontrol telah logis.

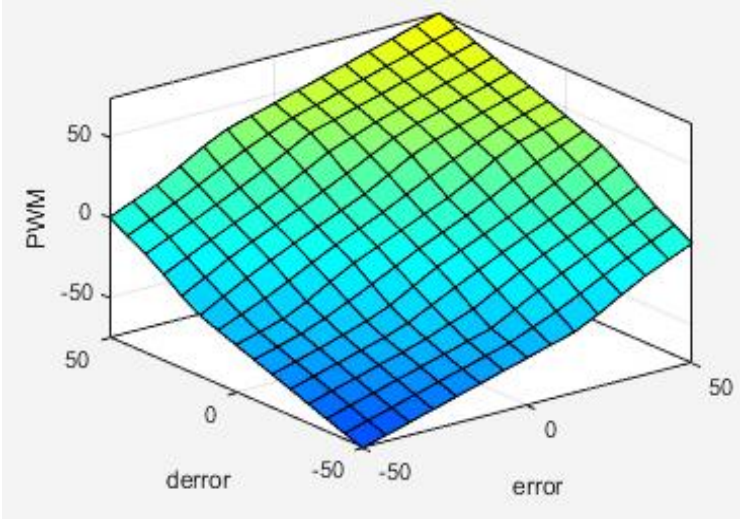

Gambar 8. Bentuk Surface

Jika error dan derror yang dihasilkan berada di kondisi negatif (e-) dan (de-), (Gambar 19), maka fuzzy memberi nilai PWM yang rendah (Gambar 18). Sebaliknya, jika derror berada di positif (e+) dan derror+, maka fuzzy memberi nilai PWM yang besar.

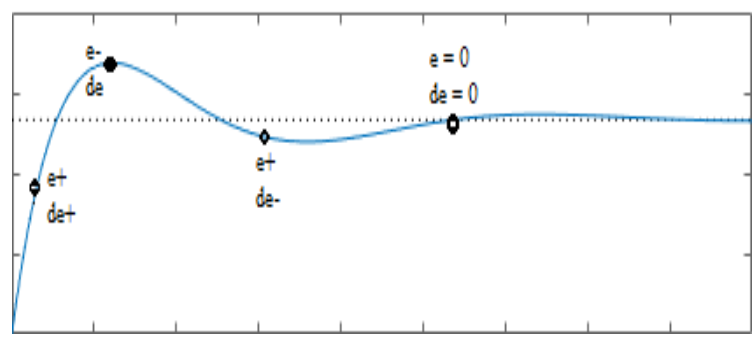

Gambar 9. Posisi Error dan dError pada Respon Waktu Sistem

\section{Pemograman pada CV AVR}

Penulisan bahasa program di CV AVR dilakukan setelah tahapan perancangan fuzzy pada MATLAB selesai. Bahasa program yang dihasilkan dalam bentuk file HEX kemudian di upload ke mikrokontroler.

Pada tahapan ini, penyesuaian (tunning) dilakukan kembali untuk menghasilkan kontrol sesuai keinginan. Angka di dalam tabel merupakan hasil dari penyesuaian (tunning) ke-2 yang telah dilakukan dari rentang nilai 15-75 PWM menjadi -24 hingga 50 PWM.

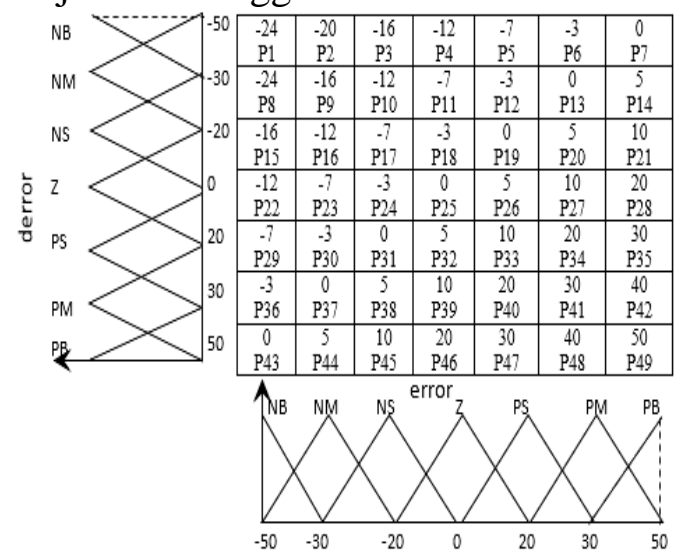

Gambar 10. Membership Function PWM

Bentuk Singleton Setelah Tunning

\section{Pengujian Sistem Kendali Kecepatan Motor}

Tujuan dari pengujian sistem motor adalah untuk mengetahui rancangan kendali motor dapat bekerja baik dan sesuai keinginan. Ada dua jenis pengujian yang dilakukan yaitu uji fungsional dan uji kinerja.

\section{Uji Fungsional}

Uji fungsional bertujuan untuk mengetahui kinerja sistem kontrol yang dihasilkan dengan cara membandingkan 
hasil sistem kontrol dengan kriteria yang ditetapkan. Kriteria yang hendak dicapai dari alat yaitu:

1. Motor dapat berputar sesuai dengan setting point, yaitu $40 \mathrm{rps}$ (130 rpm), 60 rps (190 rpm), dan 80 rps (252 rpm).

2. Menunjukkan respon waktu sistem yang stabil.

\section{Uji Kinerja}

Uji kinerja bertujuan untuk menghasilkan kecepatan putaran motor yang mencapai nilai setting point secara bertahap (soft-starting), tidak terdapat lonjakan arus atau adanya overshoot, dan menunjukkan respon waktu sistem yang stabil. Berikut alur pengujian:

1. Menyiapkan biji kedelai sebanyak $8 \mathrm{~kg}$ yang telah direndam.

2. Menimbang biji kedelai untuk mengetahui massa biji kedelai setelah perendaman. Massa biji kedelai yang telah direndam adalah $10.99 \mathrm{~kg}$

3. Memasukkan biji kedelai ke dalam bak wadah dengan perbandingan $5 \mathrm{~kg}$ biji kedelai dan 5 liter air (beban 1).

4. Mengukur torsi dengan cara mengaitkan timbangan massa pada lengan pengait yang terpasang pada poros pengaduk sebelumnya, kemudian memutar timbangan tersebut hingga kembali pada posisi semula.

5. Mengukur torsi beban dengan perulangan 3 kali, kemudian nilai akhir torsi merupakan hasil rata-rata dari data tersebut.

6. Memasang bak wadah ke mesin pengaduk.

7. Menyalakan motor dengan memutar potensiometer, yaitu: $40 \mathrm{rps}(130 \mathrm{rpm})$, $60 \mathrm{rps}$ (190 rpm), dan $80 \mathrm{rps}(252 \mathrm{rpm})$. Setiap kecepatan dilakukan perulangan 3 kali dan setiap perulangan dilakukan selama 1 menit.

8. Merekam data waktu (detik), SP (rps), kecepatan motor (rps), error e (rps), dan output fuzzy melalui Serial Port Road to MSI.
9. Merekam arus dan tegangan dengan multimeter selama proses pengadukan berlangsung.

10. Terdapat 2 perlakuan:
a. Perlakuan tanpa kontrol.
b. Perlakuan dengan kontrol.

11. Menambah beban ke dalam wadah yang sebelumnya telah berisi kedelai dan air dengan perbandingan $5 \mathrm{~kg}$ biji kedelai dan 5 liter air (beban 2).

12. Mengulangi langkah 6-11.

\section{Analisis Data}

Analisis data dilakukan dari hasil uji fungsional dan uji kinerja. Untuk mengetahui sistem kontrol yang dihasilkan telah berhasil, maka dilakukan perbandingan antara luaran sistem kontrol dengan kriteria yang telah ditetapkan pada masing-masing pengujian.

\section{HASIL DAN PEMBAHASAN}

\section{Hasil Perancangan Sistem Kendali}

Mesin pengaduk dapat dilihat pada gambar berikut:

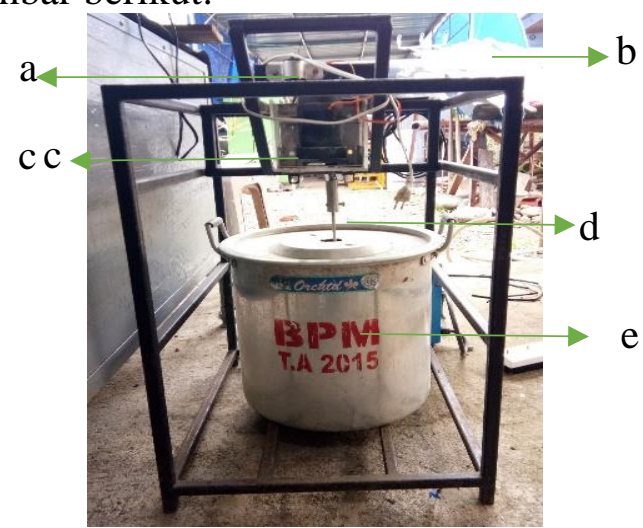

Gambar 11. Mesin Pengaduk Tampak Depan

Keterangan:

a : sensor kecepatan

b : kotak kontrol

c : motor

$\mathrm{d}$ : pengaduk

e : bak pengaduk

Perancangan sistem kendali terdiri dari beberapa komponen penyusun, yaitu catudaya untuk motor dan mikrokontroler, SSR, LCD, potensiometer, dan mikrokontroler. Gambar 11 memperlihatkan 
mesin pengaduk setelah penerapan sistem kontrol sedangkan Gambar 12 memperlihatkan sistem kontrol yang telah dibuat.

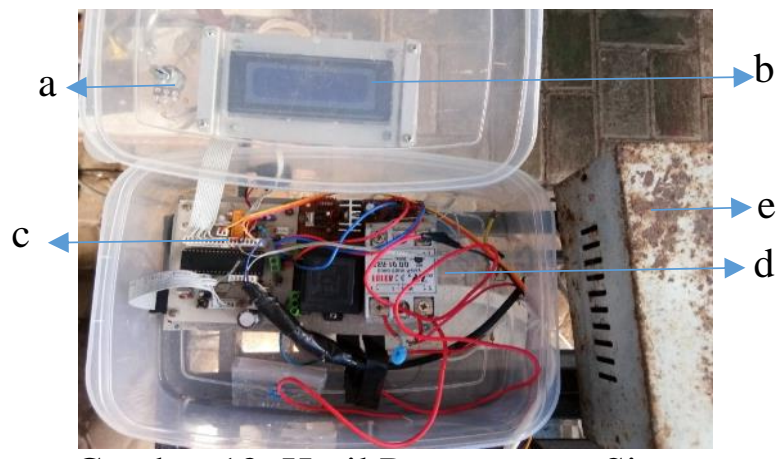

Gambar 12. Hasil Perancangan Sistem Kendali Kecepatan Motor

Keterangan:

a : potensiometer

b : LCD

c : mikrokontroler

d : SSR

e : Catu daya

\section{Hasil Uji Fungsional}

Hasil pengujian pada kecepatan $40 \mathrm{rps}$ (130 rpm), 60 rps (180 rpm), dan 80 rps (252 rpm) adalah sebagai berikut:

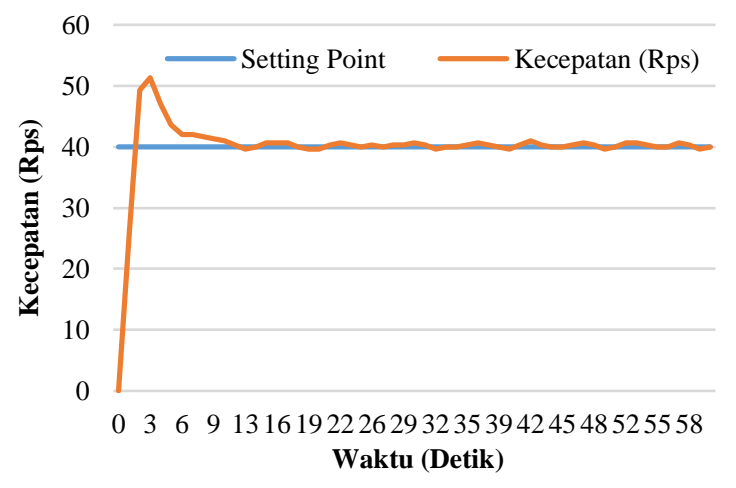

Gambar 13. Respon Waktu Kontrol Kecepatan 40 Rps (130 Rpm)

Gambar diatas merupakan bentuk respon kontrol kecepatan 40 rps (130 rpm). Gambar tersebut menunjukkan kecepatan motor mampu mencapai nilai setting point yang diinginkan, dan respon dalam kondisi stabil. Kondisi tersebut sesuai dengan kriteria yang telah ditetapkan, yaitu mencapai setting point dan respon dalam keadaan stabil. Adapun waktu settling time pada kecepatan ini adalah 14 detik.
Pada gambar terdapat kondisi overshoot sebesar $22.5 \%$ yang berlangsung selama 11 detik. Gambar juga menunjukkan adanya sedikit sedikit osilasi. Namun hal tersebut tidak berdampak pada sistem pengaduk karena selisih antara nilai setting point dan nilai osilasi tersebut hanya $1 \mathrm{rps}$ atau nilai osilasi tersebut hanya 41 rps.

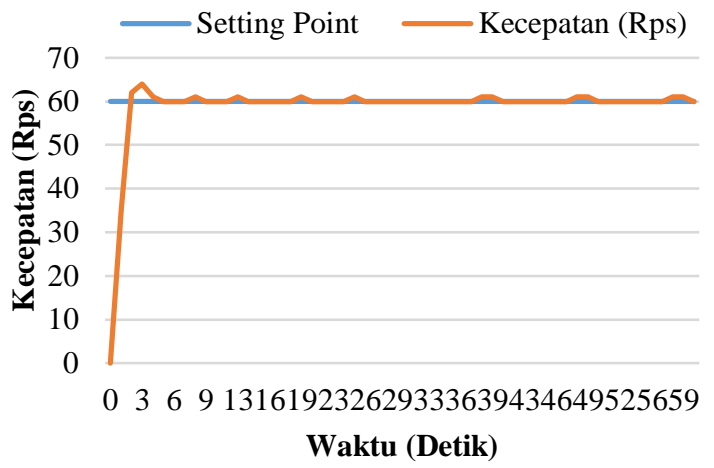

Gambar 14. Respon Kontrol Kecepatan 60 RPS (190 Rpm)

Bentuk respon waktu pada kecepatan 60 rps (190 rpm) ditunjukkan pada Gambar 14. Berdasarkan gambar tersebut, kecepatan motor mampu mencapai nilai setting point dan respon sistem dalam kondisi stabil. Kondisi tersebut sesuai dengan kriteria yang telah ditetapkan, yaitu mencapai setting point dan respon dalam keadaan stabil. Adapun nilai settling time pada kecepatan ini adalah 5 detik.

Pada gambar tersebut terdapat overshoot sebesar $6.7 \%$ selama 3 detik. Gambar juga menunjukkan sedikit osilasi namun tidak berdampak pada pengadukan karena selisih antara nilai setting point dan nilai osilasi tersebut hanya 1 rps atau nilai osilasi tersebut hanya 61 rps. 


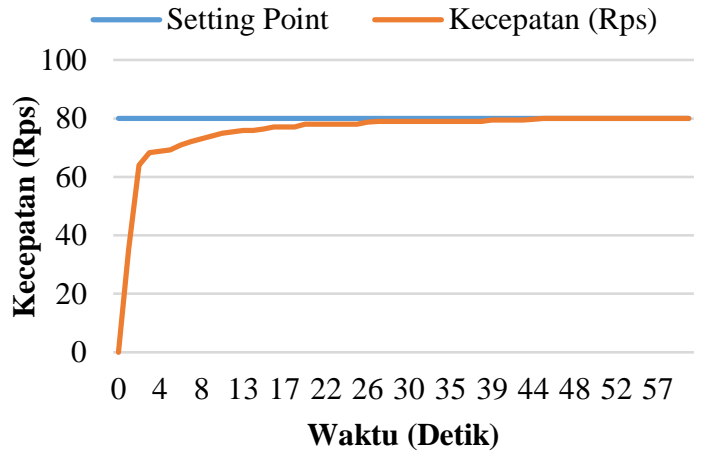

Gambar 15. Respon Kontrol Kecepatan 80 RPS

Gambar 15 merupakan bentuk respon waktu pada kecepatan 80 rps (252 rpm). Gambar tersebut menunjukkan kecepatan motor mampu mencapai nilai setting point dan respon dalam keadaan stabil. Kondisi tersebut sesuai dengan kriteria yang telah ditetapkan, yaitu respon mampu mencapai setting point dan kondisi respon dalam keadaan stabil. Adapun nilai settling time pada kecepatan ini adalah 19 detik. Berbeda pada keceparan $40 \mathrm{rps}$ (130 rpm) dan $60 \mathrm{rps}$ (190 rpm), pada kecepatan 80 rps (252 rpm) tidak menunjukkan kondisi overshoot dan osilasi.

Tabel 2. Performa Sistem Kendali Fuzzy Tanpa Beban

\begin{tabular}{ccccc}
\hline & \multicolumn{3}{c}{ Karakteristik Respon } & Kategori \\
\cline { 2 - 4 } $\begin{array}{c}\text { Kecepatan } \\
(\mathbf{r p s})\end{array}$ & $\begin{array}{c}\text { MO } \\
(\%)\end{array}$ & $\begin{array}{c}\text { Settling } \\
\text { time, } \boldsymbol{t}_{\boldsymbol{s}} \\
(\text { detik })\end{array}$ & $\begin{array}{c}\text { Offset } \\
(\%)\end{array}$ & $\begin{array}{c}\text { Respon } \\
\text { Sistem }\end{array}$ \\
\hline 40 & 22.5 & 14 & 0 & Stabil \\
60 & 6.7 & 5 & 0 & Stabil \\
80 & 0 & 19 & 0 & Stabil \\
\hline
\end{tabular}

Ketiga respon grafik ditunjukkan pada Tabel 2. Ketiga respon tersebut telah memenuhi kriteria untuk uji fungsional, yaitu kecepatan motor mampu mencapai nilai setting point dan respon waktu sistem kontrol dalam keadaan stabil. Adapun nilai settling time menunjukkan kecepatan motor meningkat secara bertahap (soft-starting).

Bentuk respon pada kecepatan 80 rps berbeda dengan kecepatan $40 \mathrm{rps}(190 \mathrm{rpm})$ dan 60 rps (252 rpm). Pada kecepatan 80 rps (252 rpm), tidak terdapat overshoot sedangkan kecepatan, $40 \mathrm{rps}(130 \mathrm{rpm})$ dan $60 \mathrm{rps}(190 \mathrm{rpm})$ memiliki overshoot dan sedikit mengalami osilasi.
Kondisi overshoot dan adanya osilasi pada Gambar 13 dan Gambar 14 dipengaruhi pada tahapan pembuatan basis aturan (rule base). Menurut Hartono (2008), hasil kinerja respon kontrol merupakan hasil representasi dari tahapan rule-base (kaidah pembicaraan). Selain itu, pengaturan fungsi keanggotaan, utamanya fungsi keanggotaan zero (nol) pada tahapan fuzifikasi, juga memengaruhi kinerja respon kontrol. Menurut Asta (2002), hasil pengendalian sangat bergantung peletakan fungsi keanggotaan zero (nol) dalam keanggotaan fuzinya. Namun, dalam perancangan ini, keadaan overshoot dan osilasi tersebut tidak memengaruhi sistem pengadukan karena nilai osilasi tersebut hanya 1 rps.

Pemberian nilai time sampling pada bahasa program juga memengaruhi sensitivitas respon atau kecepatan respon dalam menanggapi masukan. Penelitian yang dilakukan Adinandra, Pratama, dan Sahroni (2014) memperlihatkan pengubahan time sampling memengaruhi settling time, overshoot, dan ketidakstabilan pada sistem.

\section{Hasil Uji Kinerja}

Hasil uji kinerja untuk kecepatan 40 rps (130 rpm), $60 \mathrm{rps}$ (180 rpm), dan $80 \mathrm{rps}$ (252 rpm) adalah sebagai berikut:

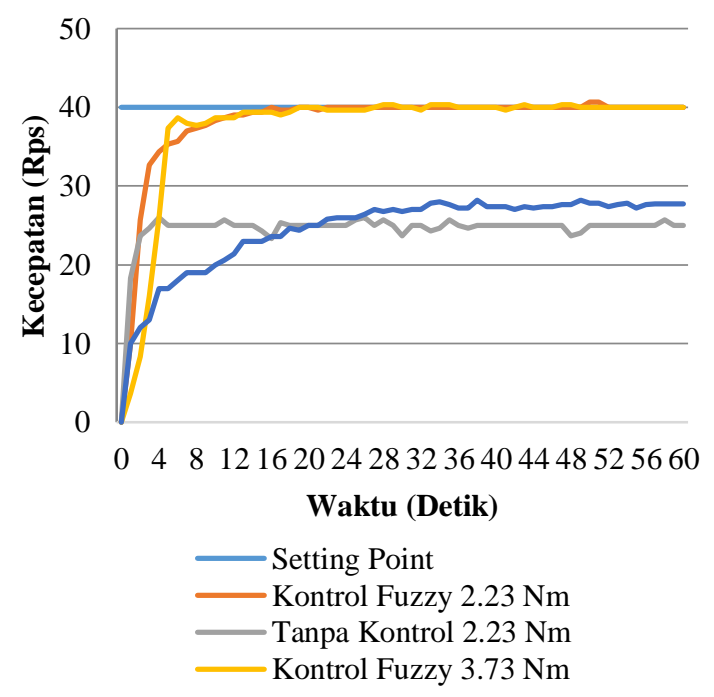

Gambar 16. Respon Waktu pada Kecepatan 40 Rps (130 Rpm) 
Gambar 16 merupakan bentuk respon waktu pada kecepatan 40 rps (130 rpm) terhadap perubahan beban $2.23 \mathrm{Nm}$ dan 3.73 $\mathrm{Nm}$. Berdasarkan gambar diatas, kecepatan putaran motor tanpa kontrol tidak mampu mencapai nilai setting point yang ditetapkan. Berbeda dengan adanya penerapan kontrol fuzzy, kecepatan motor mampu mencapai nilai setting point. Kecepatan motor mencapai setting point secara bertahap (softstarting).

Gambar tersebut juga menunjukkan tidak adanya lonjakan arus listrik atau tidak adanya overshoot. Selain itu, kondisi respon juga berada dalam keadaan stabil. Kondisikondisi tersebut sesuai dengan kriteria yang telah ditetapkan, yaitu kecepatan motor mampu mencapai setting point secara bertahap, tidak terdapat lonjakan arus, dan respon dalam keadaan stabil.

Respon dengan kontrol fuzzy tidak memiliki nilai offset karena tidak ada perbedaan antara nilai setting point dengan nilai keluaran. Ketika nilai keluaran sistem tidak sama dengan nilai masukan, maka sistem tersebut memiliki nilai offset (Ogata, 2010).

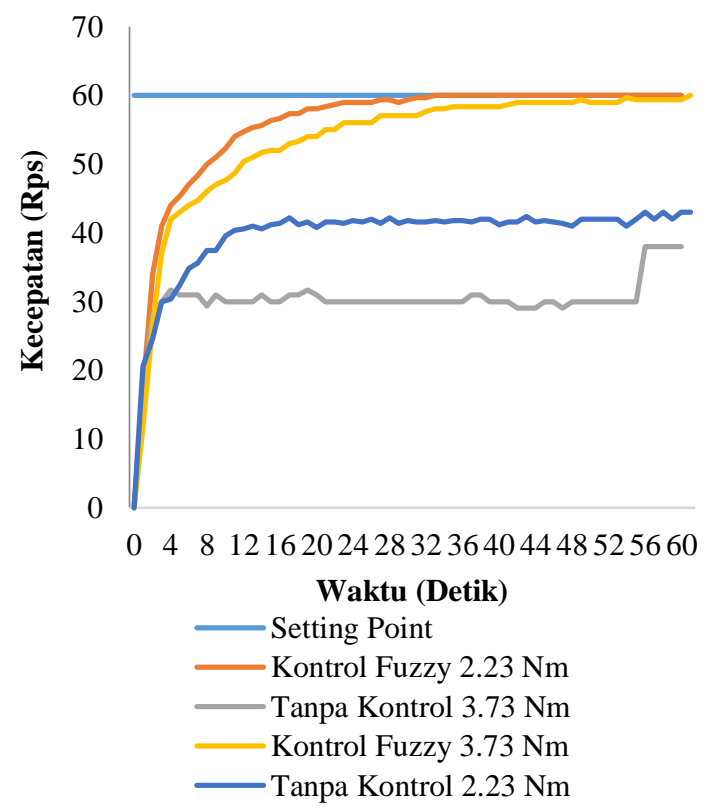

Gambar 17. Respon Waktu pada Kecepatan 60 Rps (190 Rpm)

Bentuk respon waktu pada kecepatan 60 rps (190 rpm) dengan perubahan beban
$2.23 \mathrm{Nm}$ dan $3.73 \mathrm{Nm}$ dapat dilihat pada Gambar 17. Gambar tersebut menunjukkan bahwa kecepatan putaran motor tanpa kontrol tidak mampu mencapai nilai setting point sedangkan kecepatan motor dengan penerapan kendali logika fuzzy mampu mencapai setting point secara bertahap (softstarting).

Gambar tersebut juga menunjukkan bahwa tidak terdapat lonjakan arus, tidak terdapat kondisi overshoot, respon dalam keadaan stabil, dan tidak terjadi offset. Kondisi tersebut sesuai dengan kriteria yang telah ditetapkan, yaitu kecepatan motor mampu mencapai setting point secara bertahap (soft-starting), tidak terdapat lonjakan arus, dan respon dalam keadaan stabil.

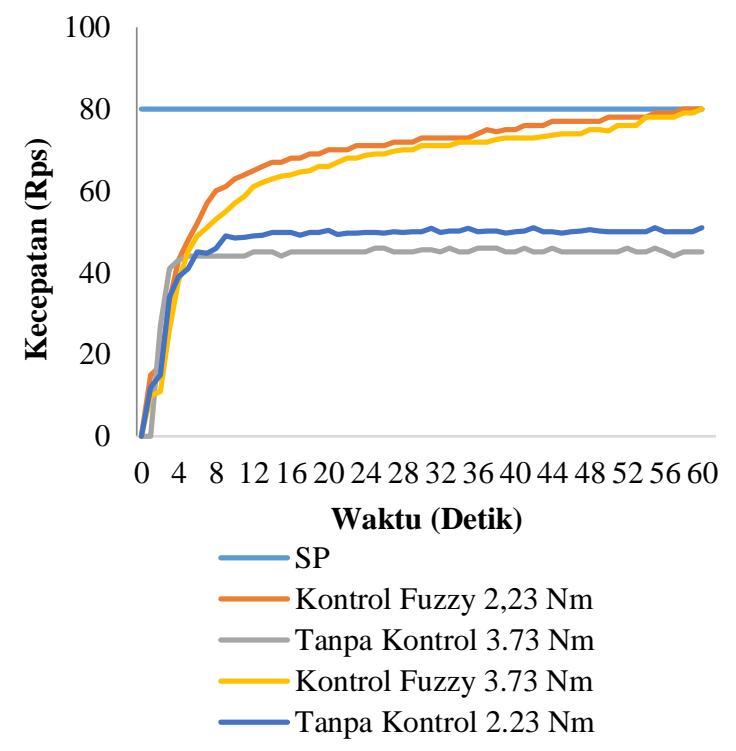

Gambar 18. Respon Waktu pada Kecepatan 80 Rps (190 Rpm)

Gambar 18 menunjukkan bentuk respon waktu pada kecepatan 80 rps (190 rpm). Kecepatan putaran motor tanpa kontrol berdasarakan gambar tersebut tidak mampu mencapai setting point yang diinginkan sedangkan dengan penerapan kontrol fuzzy, kecepatan putaran motor mampu mencapai nilai setting point secara bertahap (soft-starting).

Gambar tersebut juga menunjukkan tidak adanya lonjakan arus atau tidak overshoot, kondisi kedua respon dengan penerapan kontrol fuzzy berada dalam 
keadaan stabil. Kondisi tersebut sesuai dengan kriteria yang telah ditetapkan, yaitu kecepatan motor mampu mencapai setting point secara bertahap (soft-starting), tidak terdapat lonjakan arus atau tidak adanya overshoot, dan respon dalam keadaan stabil.

Dibandingkan saat kecepatan $40 \mathrm{rps}$ (130 rpm), dan 60 rps (190 rpm), kecepatan $80 \mathrm{rps}(252 \mathrm{rpm})$ mencapai setting point yang lebih lama. Hal ini dipengaruhi pemberian tahapan rule-base. Hal ini sesuai dengan pernyataan Hartono (2008) hasil kinerja respon kontrol merupakan hasil representasi dari tahapan fuzzy-rule. Pemberian nilai yang lebih besar pada kondisi PB (positive big) mampu memperpendek nilai settling time sehingga mencapai kondisi steady-state lebih cepat. Tabel 3 Performa Sistem Kendali Fuzzy Perubahan Beban

Berdasarkan Tabel 3 dapat disimpulkan bahwa sistem kendali yang dihasilkan telah memenuhi kriteria yang telah ditetapkan, yaitu mampu mencapai setting point, tidak mengalami lonjakan arus atau tidak terdapat overshoot, dan respon waktu sistem kontrol yang dihasilkan dalam keadaan stabil. Selain itu, kecepatan motor mencapai setting point secara bertahap (softstarting).

Respon waktu yang dihasilkan oleh sistem kontrol, mulai dari tahapan uji fungsional hingga tahapan uji kinerja, menunjukkan bahwa keseluruhan respon memiliki kondisi yang stabil. Karakter dinamik yang paling penting dari sistem kontrol adalah kestabilan, apakah stabil atau tidak. Gunterus (1994) juga menyatakan pentingnya memerhatikan bentuk respon sistem dalam pengendalian proses karena berkaitan dengan mutu produk, peralatan, efisiensi alat yang diterapkan oleh sistem kendali tersebut yang dihasilkan. Sistem yang tidak stabil dihindari karena dapat membahayakan operator, perlatan yang digunakan, mutu produk yang dihasilkan, serta efisiensi yang dihasilkan.

Respon pengujian bahan tanpa kontrol tidak mampu mencapai setting point yang diinginkan. Berbeda dengan adanya kontrol logika fuzzy mampu mencapai setting point yang diinginkan karena kontrol fuzzy mengatur pemberian PWM pada motor sesuai dengan kebutuhan setting point motor yang hendak dicapai. Penelitian yang dilakukan Apriyanto, Sumardi, dan Setiyono (2014), menggunakan PWM sebagai sinyal keluaran kontroler yang dikirimkan ke dalam motor DC untuk nantinya sehingga dapat mengatur putaran motor.

\section{Penggunaan Arus Listrik}

Pengukuran arus listrik bertujuan untuk mengetahui besarnya penggunaan arus listrik pada motor yang dikendalikan logika fuzzy dan tanpa kontrol. Berdasarkan hasil pengukuran, nilai arus listrik yang terpakai pada ketiga kecepatan 40 rps (130 rpm), 60 rps (190 rpm), dan 80 rps (252 rpm) berubah-ubah.

Tabel 3. Hasil pengukuran arus listrik system control

\begin{tabular}{|c|c|c|c|c|c|}
\hline \multirow{2}{*}{$\begin{array}{c}\text { Kece } \\
\text { pa } \\
\text { tan } \\
(\text { rps })\end{array}$} & \multicolumn{2}{|c|}{ Offset (\%) } & \multicolumn{2}{|c|}{$\begin{array}{c}\text { Maximum } \\
\text { Overshoot, MO } \\
(\%) \\
\end{array}$} & \multirow{2}{*}{$\begin{array}{l}\text { Kate } \\
\text { gori } \\
\text { Resp } \\
\text { on } \\
\text { Siste } \\
\text { m }\end{array}$} \\
\hline & $\begin{array}{c}\text { Beban } \\
2.23 \\
\text { Nm }\end{array}$ & $\begin{array}{c}\text { Beban } \\
3.73 \\
\text { Nm }\end{array}$ & $\begin{array}{c}\text { Beban } \\
2.23 \\
\mathrm{Nm}\end{array}$ & $\begin{array}{c}\text { Beban } \\
3.73 \\
\text { Nm }\end{array}$ & \\
\hline 40 & 0 & 0 & 0 & 0 & Stabil \\
\hline 60 & 0 & 0 & 0 & 0 & Stabil \\
\hline 80 & 0 & 0 & 0 & 0 & Stabil \\
\hline
\end{tabular}

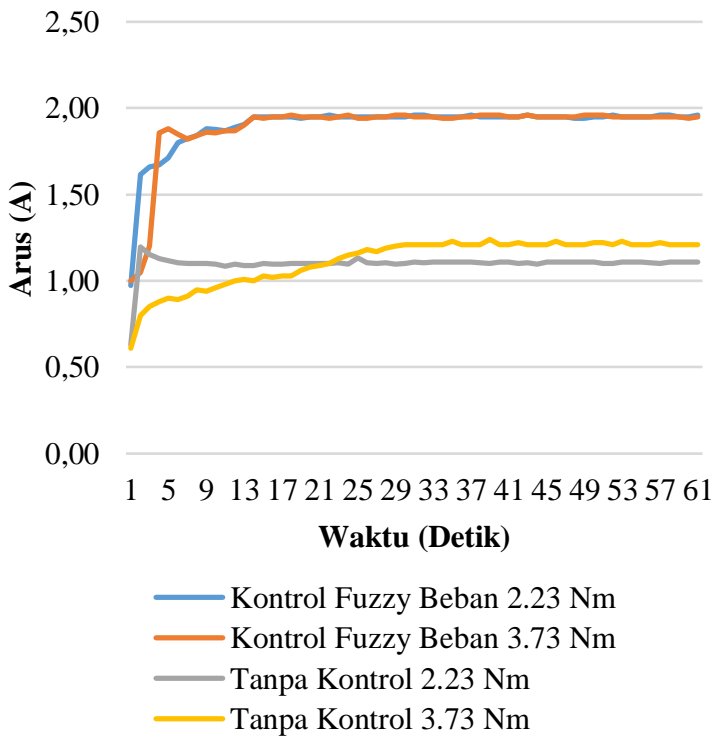

Gambar 19. Penggunaan Arus Listrik pada Kecepatan 40 Rps (130 Rpm) 
Gambar 19 menunjukkan arus yang terpakai pada kecepatan $40 \mathrm{rps}(130 \mathrm{rpm})$. Motor yang dikendalikan oleh logika fuzzy menggunakan arus sebesar 1.95 A baik pada beban $2.23 \mathrm{Nm}$ dan $3.73 \mathrm{Nm}$, sedangkan motor tanpa kontrol menggunakan arus 1.1 A untuk beban $2.23 \mathrm{Nm}$ dan 1.21 A untuk beban $3.73 \mathrm{Nm}$. Bentuk perubahan arus mengikuti bentuk respon waktu pada kecepatan 40 rps (Gambar 16). Pada gambar juga menunjukkan bahwa tidak adanya lonjakan arus pada kecepatan ini.

Gambar tersebut juga menunjukkan nilai settling time pada pembebanan 2.23 $\mathrm{Nm}$ dan $3.73 \mathrm{Nm}$ adalah 13 detik. Hal tersebut menunjukkan nilai settling time tersebut baik untuk kinerja pengaduk.

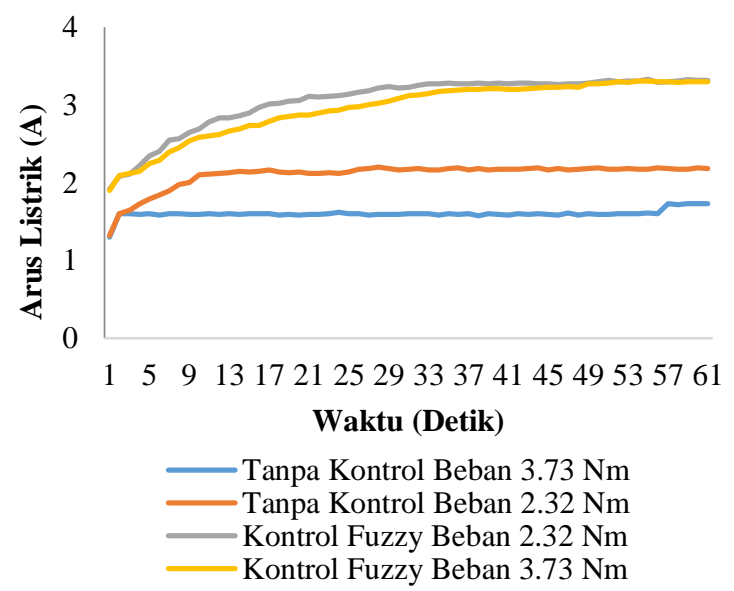

Gambar 20. Penggunaan Arus Listrik pada

Kecepatan 60 Rps (180 Rpm)

Gambar 20 menunjukkan penggunaan arus listrik pada kecepatan $60 \mathrm{rps}(180 \mathrm{rpm})$. Motor yang dikendalikan oleh logika fuzzy menggunakan arus menggunakan arus sebesar 3.3 A pada beban $2.23 \mathrm{Nm}$ dan 3.73 $\mathrm{Nm}$ sedangkan motor tanpa kontrol menggunakan arus 2.16 A pada beban 2.23 $\mathrm{Nm}$ dan 1.6 A pada beban 3.73 Nm. Gambar diatas tidak menunjukkan adanya lonjakan arus dan bentuk perubahan arus mengiktui bentuk respon waktu pada kecepatan 60 rps (Gambar 17).

Respon sistem dengan penerapan kontrol fuzzy menunjukkan nilai settling time pada pembebanan $2.23 \mathrm{Nm}$ adalah 23 detik sedangkan nilai settling time pada pembebanan $3.73 \mathrm{Nm}$ adalah 42 detik. Nilai settling time tersebut menandakan bahwa kecepatan motor meningkat secara bertahap atau nilai tersebut baik untuk kinerja mesin pengaduk.

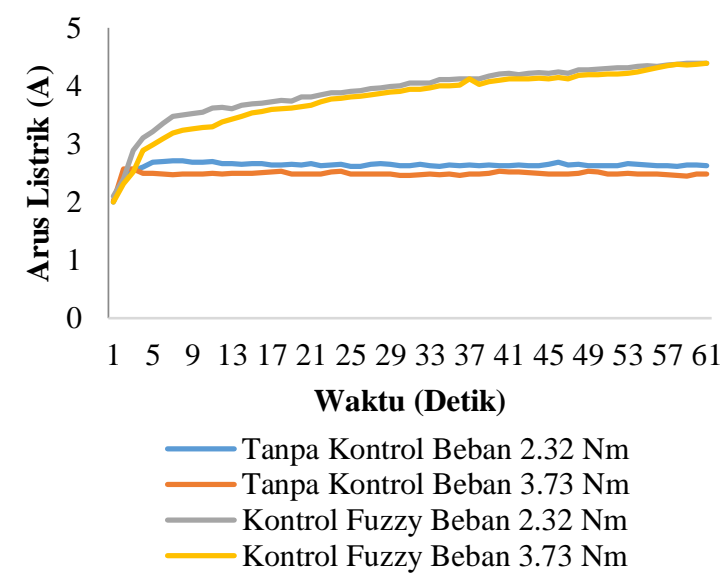

Gambar 21. Penggunaan Arus Listrik pada Kecepatan 80 Rps (180 Rpm)

Penggunaan arus pada kecepatan 80 rps (252 rpm) ditunjukkan pada Gambar 21. Arus yang terpakai jika menggunakan motor kontrol fuzzy adalah 4.39 A, baik pada beban $2.23 \mathrm{Nm}$ dan $3.73 \mathrm{Nm}$, sedangkan sistem tanpa kontrol menggunakan arus $2.63 \mathrm{~A}$ pada beban $2.23 \mathrm{Nm}$ dan $2.45 \mathrm{~A}$ pada beban $3.73 \mathrm{Nm}$.

Gambar 19, Gambar 20, dan Gambar 21 menunjukkan besarnya penggunaan arus terkait dengan kecepatan yang dihasilkan. Arus yang terpakai jika menggunakan kontrol fuzzy lebih besar dibandingkan dengan sistem tanpa kontrol. Arus yg lebih besar tersebut dibutuhkan agar sistem mampu mencapai nilai setting point yang diinginkan. Sistem tanpa kontrol menggunakan arus yang lebih sedikit sehingga sistem tanpa kontrol tidak mampu mencapai nilai setting point.

\section{KESIMPULAN}

1. Telah berhasil merancang sistem kendali kecepatan putaran motor untuk mesin pengaduk bahan pertanian dengan kinerja yang baik.

2. Kinerja sistem kontrol fuzzy mampu mencapai nilai setting point, tidak adanya lonjakan arus listrik atau tidak 
terdapat overshoot, tidak memiliki offset, dan kecepatan motor dalam keadaan stabil.

\section{DAFTAR PUSTAKA}

Asta, D. (2002). Fuzi Adaptif dengan Penalaan Fungsi Keanggotaan pada Pengendali Motor DC Berbasis Mikrokontroler AT89C52. Yogyakarta: UGM.

Gunterus, F. (1994). Falsafah Dasar: Sistem Pengendalian Proses. Jakarta: Elex Media Komputindo.

Hartono, P. (2008). Analisis Pengendali Kecepatan Motor DC Menggunakan Logika Fuzzy dengan PWM. Bandung: ITB.

Jamshidi, M. (1996). Large-scale Systems: Modeling, Control, and Fuzzy Logic. USA: Prentice-Hall.

Ogata, K. (2010). Model Control Engineering. New Jersey: Prentice Hall.

Sahroni, A., Adinandra, S. \& Pratama, R. W. (2014). Analisis Efek Tunda Waktu (Time sampling) Terhadap Performansi Sistem Kendali Jaringan Berbasis ZigBee IEEE 802.145.4. Jurnal Rekayasa Teknologi Industri dan Informasi, 155-160. 